\title{
ANCHIETA E AS CANÁRIAS
}

Há mais de meio século, Sílvio Romero escreveu: "Anchieta é geralmente considerado um português..." (2). Enquanto vivo o ardoroso e combativo polemista sergipano, ninguém ousou opor-lhe embargos à assertiva, porque the temiam os impulsos da linguagem violenta e vergastante. $\mathbf{E}$ daí não ter sido contestado nem depois de morto.

Professôres de literatura e história deixaram passar a afirmativa. Nem apelaram da sentença proferida. No entanto, porque a repeti, logo se levantou grande celeuma em tôrno do assunto. Chamaram-me de ignorante em assuntos históricos. Protestos pipocaram. Quiseram-se arrazar com gana. "Gana! Admirabel palabra! Gana, explica Miguel de Unamuno, término de origen germánico probabelmente - aunque el español sea la lengua latina más latina, más que el italiano; la que contiene menos elementos germánicos - gana es algo como deseo, humor, apetito. Hay ganas de trabajar y sobre todo ganas de no hacer nada. Como decia el otro: "No es que no tenga ganas de trabajar, es que que no tengo ganas de no trabajar" (3). E em português o vocábulo gana tem o mesmo sentido para ser empregado nos mesmos 'casos.

Ora, o assunto em foco devia ser debatido com Sílvio Romero, enquanto vivo. Para êle, "Anchieta é geralmente considerado um português", pelo nascimento ou pela cultura. Ou pelas duas coisas. Anchieta estudara latim e lógica no Colégio dos jesuítas em Coimbra, dos catorze aos dezoito anos, quando é recebido como Irmão na Companhia de Jesús e mandado para o Brasil, onde vem servir como secretário do Padre Manoel da Nóbrega, formado em direito canônico pela Universidade de Coimbra. E como Irmão fica até 1567, treze anos após a fundação da Metrópole Nobreguense, quando por mandado de Nóbrega vai à Bahia para receber as ordens de Padre.

Mas Sílvio Romero fêz a afirmativa sem o menor esclarecimento. Agora, nem seus descendentes julgam-se no direito de emendar-1he o desacerto, se é desacerto. Nos mesmos casos, outras corrigendas poderiam ser reclamadas. Assim, Julio Cejador y Frauca em conferência pronunciada no Ateneu de Madrí, por oca-

\footnotetext{
(1). - As provas do artigo anterior foram enviadas ao Prof. Tito Livio Ferreira que, em resposta, enviou o presente trabalho ( $E$. Simōes de Paula).

(2). - Sílvio Romero, História da Literatura Brasileira, tomo II, pág. 16.

(3). - Miguel de Unamuno, La Agonia del Cristianismo. Editorial Losada, Buenos Aires, pág. 62.
} 
sião do III Centenário do Quixote, em 1905, sôbre "El Quixote y la lengua castellana", logo nas primeiras palavras assevera: "En nuestros primeros dramáticos Lope de Rueda, Lucas Fernández, Juan del Encina, Gil Vicente..."(4). Mas Gil Vicente é português da gema. Não o ignora Julio Frauca, ao inclúi-lo na lista de nuestros primeiros dramáticos, como se houvesse nascido na Espanha, na boa companhia de Lope de Rueda, Lucas Fernández e Juan del Encina. A que levou o conferencista a considerá-lo patrício, naturalmente foi o fato de o escritor português ter escrito em seu idioma e em castelhano. E no século seguinte, D. Francisco Manoel, outro português, pratica a mesma proeza.

Nem assim os portuguêses protestaram contra a afirmativa de Frauca. Nascido em Portugal, Gil Vicente é uma glória das duas literaturas peninsulares. Glória autêntica do bilingüismo. Outros exemplos do universalismo lusíada não faltam. Cito apenas Santo Antônio de Lisboa para os portuguêses, porque nasceu nesta cidade, e Santo Antônio de Pádua para os italianos, porque lá morreu, identificado na mesma e única pessoa portuguêsa: Fernando de Bulhões. Italianos reivindicam para si a glória de lhe guardarem o túmulo. Portuguêses consagram-1he amor, ternura e devoção, porque Lisboa é o berço do famoso santo, representante máximo do franciscanismo cristão lusitano, e doutor da Igreja. E no Brasil, Santo Antônio teve as honras de oficial do Exército.

Mas a afirmação de Sílvio Romero não pode nem deve ser desprezada. O eminente historiador argentino Henrique D. Gandia escreve: "Rómulo D. Carbia, en repetidas ocasiones trató de demonstrar que el oceano no estaba dividido entre los reys de España y Portugal por una linea que iba de este a oeste pasando por el cabo de Bojador, sino por un meriaiano, o sea, otra línea que corria del norte a sur por entre las Islas Canárias. Para ello se basó en el hecho de que en el tratado de 1480 se habla de "marquas" o "termos", que "sam das Canárias para baixo e adiante contra Guinéa." (5). O período está claro. Dispensa comentários. O Meridiano devia passar, no entender de Carbia, por entre as Ilhas Canárias, de forma a dividi-las ao meio. Merece o melhor conceito de Jônatas Serrano, historiador e professor do Colégio Pedro II e do Instituto de Educação do Rio de Janeiro, já falecido, a cultura de Rómulo D. Carbia. Em sua obra, Jônatas Serrano (6) fala do professor da Universidade de la Plata nos seguintes têrmos: (7) "A Introdução é um notável ensaio sôbre o problema do conhecimento histórico. Há notas com preciosas informações bibliográficas dos principais autores que têm tratado do modo por que se deve escre

(4). - Cervantes, Don Quixote de la Mancha, Joaquim Gil Editor, Buenos Aires.

(5). - Henrique $\mathrm{D}$. Gandia, Historia de Cristobal Colon, pág. 255.

(6). - Jônatas Serrano, Como se ensina a História, Editôra-proprietária Cia. Melhoramentos de São Paulo. Biblioteca de Educação, vol, XXV, pgs. 151 e 1.52 .

(7). - Rómulo D. Carbia, Historia de la Historiografia Ar ́śntina, vol. I (Biblioteca Humanidades, tomo II. La Plata, 1925). 
ver a história". O juízo de Jônatas Serrano merece acatamento. Não era homem de opiniões aligeiradas. E não receava expô-las, quando necessário a tempo e à hora.

Rómulo D. Carbia tinha razões para defender o meridiano e não o paralelo. No seu entender, aquêle devia passar pelo meio das ilhas Canárias: metađe para Portugal, metade para a Espanha. Embora tivesse opositores, não hesitou em defender a sua tese. O mesmo fato se observa quanto ao meridiano de Tordesilhas, onde se traçaram as primeiras fronteiras ideais do Brasil, seis anos antes da viagem de Pedro Álvares Cabral. A respeito da demarcação da linha convencionada, jamais Portugal e Espanha se entenderam. Em substancioso ensaio histórico-geográfico sôbre "As fronteiras legais da Colônia de São Vicente", o erudito historiador Américo de Moura (8) estuda o problema do traçado seguido pelo meridiano de Tordesilhas. Para êle, a linha declinava para o oeste e chegava até o rio Paraguai e o estuário do Prata. Nesse caso, o Paraguai pertencia à Corôa Portuguêsa. Mas o trabalho de Américo de Moura merece atenta leitura. E por êle se avaliará de sua cultura e honestidade.

Não só o tratado de 1480 e o de Tordesilhas originaram debates entre os historiadores. Nesse caso estão o de Madrí, de 1750, e o de Santo Ildefonso, de 1777, realizados entre Portugal e Espanha. O primeiro foi elaborado pelo gênio diplomático do santista Alexandre de Gusmão. Procuraram êsses dois tratados es- tabelecer os limites entre as terras da Corôa Portuguêsa $e$ as da Corôa de Espanha, na América do Sul. Nenhum dos dois tratados foi cumprido. Coube ao Barão do Rio Branco, em começos do século atual, a glória de fazer diretamente, com as nações vizinhas, tratados definitivos para a demarcação de nossas fronteiras, já assinaladas, pouco mais ou menos, no tratado de Madrí, graças aos portuguêses de São Paulo, aos paulistas fixados nas bacias do São Francisco e do Amazonas. E não tivessem os homens de São Pau1o "tecido os fortes laços de coesão nacional que a êles se devem", assevera Américo de Moura, isso não seria possível.

Nesses casos, ocorre-me a frase de Calderon de la Barca: "La vida és sueño e los sueños sueños son". Respeito a tratados e respeito a sonhos, ambos merecem ser interpretados. Voltando a Miguel de Unamuno, lembro-lhe a frase: "Y hasta narrando historia se hace - historia" (9). Com tratados tambem se "hace historia", embora nem sempre sejam cumpridos pelas partes interessadas. $\mathbf{E}$ os tratados ilustram as páginas da história, iluminando-as.

\footnotetext{
(8). - Américo de Moura, As fronteiras legais da Colônia de São Vicente, in "São Paulo em Quatro Séculos". Edição do Instituto Histórico e Geográfico de Sãs Paulo, 1953, pág. 153.

(9). - Ob. cit., pág. 38 .
} 
Regressemos a Anchieta. Que era português afirmara-o Sílvio Romero. Pelo nascimento, pela cultura, pelos reis a quem serviu. O autor da "História da Literatura Brasileira", silencia. Mas, como para Ortega y Gasset a história é "el hombre y su circunstancia" (10), seria muito simplista qualquer afirmativa sem entreligarmos o homem e a circunstância, isto é, o contôrno que o condiciona. E por isso mesmo, o autor citado acrescenta: "A canção da história é preciso cantá-la inteira" (11).

$\mathrm{Na}$ paisagem histórica do século XVI, Anchieta surge a serviço de Portugal. A serviço da Corôa Portuguêsa realiza grandes trabalhos. D. João III tem papel proeminente na projeção apostólica anchietana e xaveriana. Ainda há pouco tempo, Adro Xavier, escritor espanhol, escreveu um livro sôbre o apóstolo do Oriente (12). Sem querermos entrar no mérito da obra, porque esta já foi devidamente analisada pelo Padre Domingos Maurício, S. J. em "Uma pseudobiografia Xaveriana" (13), a certa altura dêsse trabalho, Adro Xavier fala de São Francisco Xavier na Ásia, para indagar: "Quem o envia? (a Goa) Quem é o responsável desta estranha missão que oculta a cabeça da jerarquia entre brenhas?" (14). Informa-lhe o Padre Domingos Maurício, S. J., "Quem soubesse história, responderia: D. João III, que o pediu; o Papa, que lho concedeu; Xavier, que o aceitou. Três pessoas distintas e uma só explicação verdadeira". Cum Anchieta đá-se o mesmo caso. Tanto Anchieta quanto os seus companheiros estavam aqui a serviço de Portugal e pagos pela Corôa Portuguêsa. Cada jesuíta recebia um cruzado para exercer a catequese. Daí o Padre Manoel da Nóbrega, primeiro provincial da Companhia de Jesús no Brasil, ter criado o ensino oficial em nossa terra, por instruções recebidas diretamente de D. João III. Ao tratar do problema, o Padre Domingos Maurício, S. J. (15) pergunta: "Que interferência teve Portugal no apostolado xaveriano? (A mesma pergunta pode ser feita em relação ao apostolado nobreguense e anchietano). E porque, em história, tal qual como na física, os homens e as instituições, as idéias e os fatos não escapam à lei constante da açãoreação, que interferência teve o apostolado xaveriano (nobreguense ou anchietano) na história de Portugal?" E Padre Domingos Maurício, S. J., observa: "Não se trata de explorar, sob estímulo dum nacionalismo descabido, a oportunidade dêste centenário (de São Francisco Xavier) para envolver qualquer país obscuro na capa magna das refulgências do apóstolo. Trata-se, simplesmente, de situar uma figura nobilíssima na perspectiva justa de seu tempo e de seu meio. Os homens enquadrados pelas instituições, con-

(10). - Ortega y Gasset, Obras completas, Madrid, 1947, tomo V, págs. 21 e segs.

(11). - Ibidem, tomo VI, pág. 237.

(12). - Adro Xavier, Huellas en la arena. San Xavier en la India. Impressiones de viaje. S. A. Mayor, 81. Madrid, 1952 .

(13). - In Brotéria, Lisboa. MCMLII, val LV.

(14). - Adro Xavier, op. cit., págs. 53-54.

(15). - Op. cit. 
dicionadas ao ambiente em que se movem, agindo ou reagindo sôbre êle, tal qual na fenomenologia da natureza, dão-nos a medida exata dos seus ideais e das suas realidades, dos seus triunfos e dos seus fracassos, das suas virtualidades e dos seus limites. No caso do santo apóstolo das Indias, se o presente estudo pretende possibilitar, de relance, a visão retrospectiva de quanto São Francisco Xavier deve a Portugal, abrirá margem para reconhecer, também, quanto Portugal deve a São Francisco Xavier. Muitos portuguêses, descortina a história na vida do grande navarro. O primeiro, pela categoria e alcance de suas interferências, é, sem dúvida, $\mathbf{D}$. João III".

O mesmo se verifica em relação a Anchieta. Anchieta deixa as Canárias aos catorze anos. Quatro anos mais tarde entra como Irmão na Companhia de Jesús. Para servir Portugal, D. João III manda-o para o Brasil, onde fica às ordens de Manoel da Nó. brega, como seu secretário. E morre no Brasil a serviço da Corôa Portuguêsa.

Do apóstolo da Ásia, Padre Domingos Maurício S. J., diz (16): "Desta sorte, Xavier, que pela mão de D. João III, em 1542, entra nos caminhos laboriosos do apostalado, através dos quais havia de percorrer cêrca de 100.000 quilômetros, ia, subir, agora, por por idêntico gesto, nos esplendores apoteóticos da canonização, que a Igreja promulgaria a 12 de março de 1622 , pelo oráculo de Gregório XV. Na trajetória de uma vida, a história, aplicando as palavras de Ortega y Gasset, é o "homem". Mas, sendo também "a sua circunstância", não sabemos de ninguém que, como D. João III, concorresse, para que a de Xavier, apóstolo santo, sendo tão gloriosa e fecunda, o pudesse ser tantö". Pode-se dizer o mesmo de Anchieta. Não sei de ninguém que, como Nóbrega, - "o inesquecível e tão ingratamente esquecido Padre Manoel da Nóbreba" - no dizer de Capistrano de Abreu, houvesse concorrido tanto, para que Anchieta, apóstolo santo, tivesse a existência gloriosa que teve. Por isso mesmo, Capistrano de Abreu dizia: "Quanto mais estudo Anchieta mais admiro Nóbrega". E daí Anchieta ser a mais pura glória de Nóbrega.

Já é tempo de encerrar o assunto. Se Anchieta é a mais pura glória de Nóbrega, dela estão contentes os portuguêses. Assim, em meados de maio último, em Madrí, no discurso de saudação dirigido pelo General Francisco Craveiro Lopes, presidente da República Portuguêsa, ao Generalíssimo Francisco Franco, chefe do govêrno espanhol, disse aquêle: "Anchieta, o espanhol que nos ajudou (aos portuguêses) a fazer São Paulo". Ninguém contestou a afirmativa do chefe do govêrno português. Segundo parece, todos se regosijaram. Protestos não se registaram. Nem seria eu, brasileiro

$\overline{(16) .-O p . ~ c i t . ~}$ 
e paulista, por mercê de Deus, conforme disse outrora o Padre Feijó, que iria quebrar essa harmonia tão digna e tão louvável. E "no digo más", consoante se expressava D. Quixote.

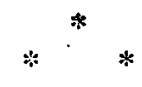

Agradeço, de coração, ao meu caro amigo e distinto colega, Professor Eurípedes Simões de Paula, a gentileza e a honra que me outorgou, de mais uma vez escrever para a Revista de História, publicação que tanto enobrece a cultura histórica em nossa terra.

TITO LIVIO FERREIRA

Professor de História Antiga e Medieval da Faculdade de Filosofia de São Bento, da Pontificia Universidade Católica de São Paulo. 